\title{
Wang Zengqi's View on Literary Language
}

\author{
Liu Xiaojing ${ }^{1}$
}

\author{
${ }^{1}$ (Wuhan Research Institute, Jianghan University, Wuhan 430056, Hubei) \\ claire889@126.com
}

\begin{abstract}
Systematic arrangement and brief discussion of Wang Zengqi's literary language view. On the basis of constantly summing up his creative experience, Wang Zengqi formed a relatively complete view of literary language. He established the ontology of the language of the novel, the language is the noumenon of the novel, and writing a novel is writing language. Wang Zengqi realized that Chinese characters are hieroglyphs and have four tones. Chinese people think in Chinese characters, and Chinese language is musical.He use Chinese traditional "wenqi theory" to interpret the relationship between language and syllables and the importance of syllables and words. Starting from the uniqueness of Chinese characters and Chinese, he explained the characteristics of literary language content, culture, suggestion, and fluidity. He established the aesthetic standard of literary language-plain, the only standard of language: accuracy. From the perspective of how a writer can improve the personality and artistic expression of literary language, he believes that literary language must seek language resources from spoken language, classical Chinese, and dialects, and draw nourishment from Chinese classical literature and folk literature. He advocated using four-character sentences and short sentences appropriately. On the basis of Qian Zhongshu's promotion of opening up Chinese and Western literature, he advocated opening up contemporary literature and classical literature (national tradition), and opening up contemporary literature, classical literature, and folk literature.
\end{abstract}

Keywords: Wang Zengqi, literary language, culturality, fluidity, suggestiveness

\section{INTRODUCTION}

Wang Zengqi is a famous novelist and essayist in contemporary China. In his long-term literary creation and practice activities, he formed his own literary language view. For a long time, people only used language as a tool to understand literary works. Wang Zengqi challenged the traditional literary theory and raised language to the height of the ontology of "language is content". Wang Zengqi is the most representative writer in the process of the transformation from instrumentalism to ontology in literary language in the new era. Wang Zengqi believes: "Language is content." "Writing a novel is writing language." [1] In his article "The Essence of Short Stories", he said: "A short story writer is an artist of one language." [2] Wang Zengqi I think that literary works are originally the art of language, just like painting, they are the art of lines and colors. Music is the art of melody and rhythm. [3] Wang Zengqi discussed literary language in a series of literary theories and prefaces. The following summarizes the general context of Wang Zengqi's literary language view, which roughly includes the following seven aspects.

\section{WANG ZENGQI'S LITERARY LANGUAGE ONTOLOGY}

Wang Zengqi talked about his novel language ontology in many articles. He said in "My Creative Career": "I think language is not only form, but content itself. Language and thought exist at the same time and cannot be separated. Language is not only the so-called'carrier', it is the body of the work. ...I once said: "Writing novels is writing language. Language is a cultural phenomenon." [4] He further pointed out in the article "The Thought and Language of Novels": "I think language is content. Probably in China It was Mr. Wen Yiduo who raised this question earlier."[5]

\section{CHINESE CHARACTERS ARE HIEROGLYPHS AND HAVE FOUR TONES. THEREFORE, CHINESE PEOPLE USE CHINESE CHARACTERS TO THINK, AND THE CHINESE LANGUAGE IS MUSICAL}

He talked about the characteristics of Chinese language in the article "I Recognizing and 
Unrecognizing Myself ": It is impossible for Chinese literature to be fully Westernized and to create a"true" modernism. Because you are a Chinese, you live In the tradition of Chinese culture, this tradition is so long and omnipresent. If you want to get rid of it, you can't do it. And why do you want to get rid of it? The most inextricable thing is language.To a nation, The most basic thing in culture is language. Chinese characters and Chinese are not the same thing. Chinese literate people should think in Chinese characters instead of thinking in Chinese.... Chinese characters have four tones, which is not existing in Western writing. Yes.... Chinese characters have some very unique things, such as antithesis and tones. Antithesis can be encountered at any time. Some people say that someone uses this word instead of another word with the same meaning, which is"For the sound to sound nice "[6]

Wang Zengqi pointed out in the article "Kneading Noodles-Talking about Language": Language itself is an art, not just a tool. The language used to write novels... is visual language, not auditory language. Novels are written for people to read, not for people to listen to. Educated people in China think in Chinese characters instead of Chinese. [7] Then the words have the color, image and sound of. Chinese characters were originally hieroglyphs, which consisted of three parts: shape, sound, and meaning. Shape and sound will have an impact on meaning. Chinese people are accustomed to looking at "Chinese characters" for meaning. "Vastness" must not be small water, "trickle" must be a small trickle. ...But Chinese characters have these characteristics, so one must pay attention to them. To say that a novel is a visual language is not to say that it has no sound. As I said before, human feelings are connected. The beauty of sound is a very important factor in the beauty of language. A person with literary accomplishment and well-trained in writing will "see" its voice directly from the word. Chinese language is particularly rich in music because of its "tone", that is, "four tones". A person who engages in writing can't help but seek for a little about the way of sound. "There is a floating sound at the front, and a cut sound at the back", Shen Yue summarized the law of language sound very concisely. To put it simply, the flat sound and a cut sound should be used interlaced. [8] Writing novels is no better than writing poetry. It cannot have such strict rules, but it is necessary to pursue the beauty of language and the writer must train their ears. It is good for a person who writes a novel to write a little old poetry, opera, and opera lyrics. [9]

Wang Zengqi further talked about the musical beauty of Chinese language in his article "Literary Language Miscellaneous Talks": Chinese characters are hieroglyphs. In addition, Chinese language has a great feature, which is that the language is all 'single-sound suffixes', with every single sound. ... Chinese language has different tones, and each word has a certain tonal value, which is yin, yang, up, down, or four tones. This constitutes the musical sense of the Chinese language. ......When writing a novel, you must also pay attention to the change of the tone, in order to create the musical beauty of the work. "He advised the writer" to study the four tones of Chinese characters, and learn to write a little old poems, and we must go through this language training. "In addition, the Chinese language has another great feature, that is, antithesis.... To write a novel, you need to learn to use antithesis, which is not necessarily very neat. I wrote a novel about a temple. There are two big white trees outside the main hall of the temple. Fruit trees, namely ginkgo trees, I wrote about the changes of ginkgo trees: "in summer,full of shade;in autumn, full of yellow leaves." [10] If you don't use antithesis at all, if you don't use it, you won't be able to create an ancient and desolate mood.

Wang Zengqi said in the article "Antithesis. Level and oblique": Because of antithesis and Level and oblique, the unique language beauty and musical sense of Chinese are formed. Some people write poems, and the two words mean the same thing. They use this word instead of that word, just "for the sound sounds nice." As a contemporary writer, we should cultivate the aesthetic sense of language, the musical sense of language, and can feel which word is "sound" and which word is not "sound". When we write essays or novels today, we don't have to be so strict about antithesis and Level and oblique, but it is good to know the truth and make the writing feel rich. [11]

There is a word in linguistics called sense of language, sense of language, good language means that the writer's sense of language is good; if the language is not good, the writer's sense of language is not good. [12]

Comrades who are new to writing, don't just look at the works of contemporary writers, classical prose, classical poems, including Sanqu, but also practice writing by themselves to enrich our Chinese unique sense of language. Works with no sense of language or dull language sense will not be beautifully written. [13]

Regarding the importance of syllables and words, Wang Zengqi used Tongcheng School's exposition of "wenqi theory" in "About the Language of Novels (Notes)" to make a further discussion. He said: The Tongcheng School explained "Wenqi Theory" very concretely. Liu Dakui believes that there are three steps for the power of the text: a spirit, "the most refined part of the text"; two syllables, "the slightly thickest part of the text"; three character sentences, "the thickest part of the text". The Tongcheng School pays much attention to words and sentences. On the article, emphasize the words and sentences, the Tongcheng school honestly admits that this is the foundation of the article. Liu Dakui believes: "Scholars ask for spirit to be derived from syllables, and ask for syllables to obtain from 
words and sentences, then they will think too much." How to set syllables with words and sentences? He was very specific. "In a sentence, there is one more character or one less character; among a character, either a Level tone or a oblique tone is used; the same Level character, or a oblique character, or use a Yinping, Yangping, Shangsheng, Going, and Entering, the syllables are very different." He emphasis on the sound of words and sentences, thinking that this is the essence of literary language, is a very unique view of Chinese literary theory. Literary and artistic studies in other countries also involve the sound of language, but they have not mentioned such a high level, nor can it be said to be such incisive. This kind of view had existed before Tongcheng School. Han Yu's "Energetic, speaking is appropriate", "speaking is appropriate" includes "the length of the sentence" and " superior and inferior of the voice" However, the TongchengSchool realized this more clearly and played more fully. [14] Wang Zengqi believes that traditional linguistic theories are still useful to us today. When we use language, what we pay attention to is nothing more than two points: one is the length and the other is the The height of the voice or the low of the voice. "The accumulation of words into sentences, the accumulation of sentences into chapters, and the accumulation of chapters into articles. Read them together and see the syllables; singing and chanting, the spirit is out." A novel must have a rhythm that runs through the whole story, but every sentence must be well written first. Some young writers have realized the importance of the voice of language. The so-called "readability" must first be pleasant to the ear. [15]

\section{WANG ZENGQI PUT FORWARD THE UNIQUENESS OF LITERARY LANGUAGE: THE CONTENT, CULTURAL, SUGGESTIVE AND FLUIDITY OF LANGUAGE}

\subsection{The content of language}

Wang Zengqi said in "Self-reported": I think language has content. Language is the main body of the novel, not external, not just form or technique. To explore an author's temperament and his thoughts (his attitude to life, not his ideals), one must start with language and always be immersed in the author's language. Language is cultural. The language of the work reflects all the cultural accomplishments of the author. [16]

Language is not an external thing. It exists at the same time as the content (thought) and cannot be separated. There is no thought without language, and there is no language without thought. ...The language of the novel is saturated with the content and the author's thoughts. We sometimes read a novel and read three lines, but we can't stand it anymore, because the language is too crude. The roughness of the language is the roughness of the content. [17]

In the past, we generally said that language was a tool or means of performance. More than that, I think language is content. ......Mr. Wen Yiduo said in the article "Zhuangzi": "His words are not just tools for expressing thoughts, they seem to be goals in themselves." In my opinion, language and content are dependent at the same time and cannot be separated. When discussing language issues, Stalin said: "Language is the direct reality of thought." I think Stalin said this very well. From thought to language, there is no gap between them, and there is no saying that something passes through a thought to form language. It is not like this. Therefore, the only way for you to understand a writer's thought is language. You need to be able to feel his language to feel his thoughts. I once said to the extreme, "To write a novel is to write language". [18] The roughness of language is the roughness of content. [19]

\subsection{The cultural nature of language:}

Language is a cultural phenomenon. There is culture behind the language. Hu Shi advocated "Vernacular Chinese" and proposed the "Eight No Doctrines". His "eight nos" are all negative. Don't be like that, don't be like that. If there is no positive thing, what's the "need". He overlooked one thing: the artistry of language. [20] The ancients said that "no word has no origin" is reasonable, and language is a kind of cultural accumulation. The deeper the cultural accumulation of language, the richer the language. [20] Read more books from ancient people, so as not to "hate less when the book is used." This can be said to be "written culture". The other kind of culture is folk, oral culture. ...Some writers are farmers. But they are very familiar with oral literature. Chinese folk songs are a treasure trove, very rich,...you cannot become a good writer without reading folk songs. [twenty one]

Wang Zengqi said in the article "The Thought and Language of Novels": Language itself is a cultural phenomenon, and behind any language, there are cultural accumulations of different depths and shallows. When you read a novel, you need to determine the level of a writer's cultural literacy. First of all, you need to see how his language is, and whether he has a rich cultural heritage in language. [18] The formation of style is related to the cultural accomplishment of a writer. [22] "What is language? Of course it is culture."

The source of language and culture, one is Chinese classical works, and the other is folk culture, folk songs, folk stories, especially folk songs. [23] In addition to "written culture", there is also oral literature, and Chinese folk songs are a treasure trove. I have edited 
"Folk Literature" for several years and have benefited a lot. I even think that one cannot become a good writer without reading folk songs. [24]

\subsection{The suggestiveness of language:}

The beauty of language is not in the language itself, not in the meaning expressed on the literal, but in how much things are implied in the language, and how much information is conveyed, that is, how broad the scene that makes readers feel and " see". The ancients' so-called "extraordinary meaning" and "extraordinary sound" are justified. [25] The language must be able to arouse people's associations and make people think of many things. Therefore, don't write everything that you don't need to write, so that the reader will have no room for imagination. [26] He proposed that the beauty of language depends on how much information it conveys and implies how much things other than words. A sentence of mediocre language is one sentence, and the language of art says many sentences in one sentence. It is the so-called "extraordinary meaning, extraordinarily sound".[27]

\subsection{Language mobility}

Wang Zengqi said in "My Creative Career": Language is fluid. ... The beauty of language is not in every word and sentence, but in the relationship between words and sentences. Bao Shichen commented on Wang Xizhi's words, saying that his words looked only at each word, and they didn't feel so beautiful, or even not very smooth, but each part of the word, between words, "like an old man carrying young grandchildren, looking forward to affection, Itching related". The same goes for literary language. Sentences and sentences should reflect each other and look forward to each other. The language of a work is a whole, and it is internally connected. Literary language is not like building a wall, stacking one brick after another, but like a tree, growing together, with the sap flowing between branches, one branch moving, and one hundred branches shaking. [26]

"Wenqi" is a unique concept of Chinese literary theory. From "Wen Xin Diao Long" to "Tongcheng School" has always talked about this thing. I think it is the best, and the most specific one is Han Yu. He said: "Breath, water; words, floating objects; the water is large and big or small objects are big are all floating. The breath and the words are also the same, and the breath is strong, and the short and long words and the high and low voices are suitable. Later people summed up his theory into the four words "Energetic, speaking is appropriate." I think he made three very important points. According to my understanding, what he called "vigorous" means that the author is full of emotions and full of thoughts. I think he was the first to propose the relationship between the author's mental state and language. When a person is in good spirits, he is often talented and witty; when he is tired, he often fails to express his meaning. He proposed a language standard: appropriate. That is appropriate and accurate. Many writers in the world have said that "There is only one best statement for every sentence." For example, Flaubert. He further concretized "appropriate" into "the length of words" and "the superiority of the voice." The mystery of language, to put it bluntly, is just a combination of long sentences and short sentences. ... One of the characteristics of the Chinese language is the "four tones". "Sounds are high and low" not only creates a kind of musical beauty, but also directly affects meaning. Not only writing poems, but also writing prose and novels, you must also pay attention to the tone. The composition of intonation is closely related to the "four tones". [28]

The Chinese love to use water as a metaphor for articles. Han Yu said. Su Dongpo said: "My writings are like the fountain of ten thousand hustle, gushing out at any place", "but do what you should do and stop at what you can't stop." Flowing water is the best image of language. The Chinese say 'run text', which is a good way of saying. Language operates internally. Without inner movement, such language will be lifeless and dull. [28] He wrote in "The Preface to Collected Works": I have figured out the suggestiveness and fluidity of the language in "Language Issues in Chinese Literature", and I have never seen it in any book. [29]

In his article "Return to Realism, Return to National Tradition", Wang Zengqi pointed out: "Tongcheng School" is a master of ancient Chinese essays and cannot be completely defeated. They have a thorough understanding of the text and pay attention to how the article rises and falls. There is a set of rules. [30] The Tongcheng School explained the "Wenqi Theory" very concretely. What they call "wenqi" is actually the inner rhythm of language and the sense of flow of language. [31]

\section{THE AESTHETIC STANDARD OF LITERARY LANGUAGE: PLAIN}

Wang Zengqi said in "The Preface to "The Collection of Dinner Flowers": "In terms of style, I tend to write more plainly consciously " [32] In the past few years, I have paid more attention to the inheritance of traditional literature. ... Chinese traditional literary theory and painting theory are very influential. I have a teacher in junior high school who teaches me Guiyouguang's articles. Gui Youguang writes ordinary characters in light style, which has an impact on me. [33] The ancients in China had a tradition of advocating "plain" articles, and believed that "plain" was the perfect context of the article. Dong Qichang in the Ming Dynasty commented on painting: "To spread or not 
spread, in plain and not to plain" ("Rongtai Collection" Volume 1); Wang Youhua's "Ancient and Modern Ci" said: "The plain is made of the extreme splendor"; Yao Nai " "Book to Wang Tiefu" said: "The realm of the article is no better than plain". In Song Dynasty, Ouyang Xiu, Mei Yaochen, and Su Shi all regarded "plain" as their sect. Song and Yuan Dynasty are the heydays of plain beauty. Plain beauty is regarded as the high style of poetry, the high style of music, the high style of painting, and the high style of calligraphy. In the Ming and Qing dynasties, Li Dongyang, Wang Fuzhi, Wang Yuyang, Yao Nai and others held the "plain" proposition. Plain beauty was unparalleled extolled in the late period of Chinese feudal society. Wang Zengqi continued Laozi, Zhuangzi, Si Tukong, Ouyang Xiu, Mei Yaochen, Su Shi, Yao Nai and others' literary ideas based on "plain nature".

\section{THE ONLY CRITERION FOR LITERARY LANGUAGE IS ACCURACY}

The only criterion for literary language is accuracy. [34] He wrote in "Fiction Creation Notes": "My teacher Shen Congwen told me that there is only one standard for language, which is accuracy. Find the best statement in a sentence and express it in plain language."[ 35] I want the language to be accurate and simple. [36]

\section{HOW CAN WRITERS IMPROVE THE ARTISTIC EXPRESSION OF LITERARY LANGUAGE}

Wang Zengqi said in the preface of "Year off Six Fu": Whether a writer can be regarded as a writer and whether he can gain a foothold in the writer's forest depends first of all on whether he has his own language and whether he can find one that belongs only to himself and others. Very different language. [37] He specifically talked about "Shen Congwen's style" in the article "Shen Congwen and His "Biancheng"". He said: In his own words, this "Shen Congwen style" is "full of earthy flavor" and "Classical Chinese and vernacular Chinese mixed" (see the inscription of "Selected Works of Shen Congwen's Novels" published in 1957). Some of his languages are Xiangxi dialect, as well as his personal spoken language, such as "immediately" and "as usual". There are quite a lot of classical Chinese elements in his language-classical Chinese words and classical Chinese syntax. The problem is that he arranges his hometown dialect with Mandarin, classical Chinese and spoken Chinese together. They are very harmonious, and are not "genuine". In this way, Shen Congwen's own special style is formed. His language is drawn from many aspects. [38]

He talked about the relationship between literary language and classical Chinese, literary language and spoken language, literary language and dialect in different articles.

\subsection{The relationship between literary language and classical Chinese.}

Wang Zengqi talks about Shen Congwen's stylistic strength from Chinese classical literature. He said: "Shen Congwen's first book was the "Historical Records" by Sima Qian. He repeatedly read this book. The writing of his novel is concise and precise, and there are quite a few benefit from the "Historical Records". He also reads this book. He wrote a lot of poetry and essays from the Wei and Jin dynasties. His unique style, he himself said, is "a mixture of Classical Chinese and vernacular Chinese", that is, mixing the written language of the Middle Ages with the modern spoken language with a rustic flavor." [38]

Languages that appeal to intuition, such as "withered vines and old trees ,faint crows, small bridges and flowing water, house, old road and west wind ,thin horses." Such intuitionistic language has been widely used in modern novels. [39] The boundary between classical Chinese and vernacular Chinese is not easy to draw. "All the way, autumn mountains and red leaves, old garden yellow flowers, I have arrived the boundary of Jinan", is it classical or vernacular? As long as we speak Chinese, I am afraid that we cannot get rid of certain classical sentences. [40]

Wang Zengqi believes that there are two sources of language and culture: one is Chinese classical works, and the other is folk culture, folk songs, folk stories, especially folk songs. [23] He asked young writers to have more works of Chinese classical literature. In his article "The Thought and Language of Novels", he said: Some young writers are reluctant to Chinese classical works. I would say something that is not respectful. Why does his work have a bad language? That is because there is too little cultural accumulation behind his works. It's all in the vernacular. It is impossible for a writer not to read. [23] I think young writers of the New Trends have to make up two courses, one is classical literature and the other is folk literature. [41]

\subsection{The relationship between literature and spoken language.}

Wang Zengqi said in the article "Talking about Prose": The elegant, popular, and vernacular Chinese of the article has always been quite controversial. Some people think that the more vernacular Chinese the better, the more vulgar the better. ...The Song people proposed to take vulgarity as elegance. In recent years, it has been proposed that it is elegant and popular. This is mainly literary language spoken. Literary language must be a blend of classical Chinese and spoken language, with moderate intensity and no traces, so that it can be chewy and not "water". Contemporary prose is written by 
contemporary people and is written for contemporary people. The spoken language may be a little bit more, but excessive use of spoken language, or even a large amount of market language, will appear slick. I think the language is best to be vulgar, not to lose the book bag, but also to have a cultural atmosphere. [42] In fact, Wang Zengqi intentionally or unintentionally used Shen Congwen's style as the standard of literary language-combining the written language of the Middle Ages with the modern spoken language with a rustic flavor.

\subsection{The relationship between literary language and dialects.}

Wang Zengqi said: "Probably from the Ming Dynasty, Beijing dialect became'Mandarin'. China has its own vernacular novels, which are in Mandarin.'Sanyan' and'Epai'... "The wild history of The Scholars" are mostly used. It's written in Mandarin, the national language. "A Dream of Red Mansions" is written in authentic Beijing dialect." "Mandarin is not the greatest common divisor of the national language. It does not reduce the vocabulary to the minimum, so it is a distilled water language lacking artistic expression."[ 43] Wang Zengqi advocated: "Absorb the useful elements of other prescriptions. Don't use prescriptions, first of all, the writer's hometown dialect. A person is most familiar with, understands the deepest, and can best understand its vividness, and he will use his hometown dialect, that is, "mother Tongue'." He pointed out; "It is best for a writer to know a few dialects. Sometimes in order to enhance the local flavor, the writer has to study the dialects of this place hard.... Being able to master a few dialects is also a sign of the writer's rich knowledge of life. [44]

$\mathrm{He}$ also proposed the relationship between literary language and dialects. He said: A writer "better speak several languages, at least three: one Mandarin; two mother tongues; a dialect other than the three mother tongues with sound, such as Wu dialect and Cantonese." [45] He thinks Mandarin is" A distilled water language lacking artistic expression". It is best for a writer to know a few dialects. Absorb useful ingredients from other prescriptions. Don't prescribe the words, first of all, the writer's hometown dialect. One is the most familiar, the deepest, and the most able to understand its vividness and beauty, it is one's own native dialect, that is, "mother tongue." [43] also proposed that a writer should have his own literary language. He also put forward his own outstanding insights on how a writer builds his own literary language.

In the article "Lin Jinlan's Stool Bridge", he once again talked about dialects: a person's "mother tongue" will always exist more or less in his works. Regulating one's own literary language on the basis of dialects was clearly realized by many writers in the 1980s. Language is a cultural phenomenon. The context of language is culture. The more a writer understands traditional culture and the culture of a particular region, the more distinctive his language will be. The so-called tasteless and tasteless language actually means whether the language is cultural or not (this is not directly related to the amount of reading. Some people read a lot and are well organized, and still have a life-long language tasteless.) Each dialect has a special expressive power, Special beauty. This kind of beauty cannot be replaced by another dialect, nor can it be replaced by "Mandarin." "Mandarin" is the greatest common divisor of the language and has no character. [46]

\subsection{Literary language and blank space (including Tibet).}

"Everyone only talks about three points, and it may not be enough to throw a heart." This is a vulgar philosophy of life. This must be the case when writing a novel. Li Li old man said: You can't speak out enough about writing poems and essays. You can speak out two or three tenths. speak it all out, it's meaningless. [47] "Leave half a sentence to the side of the mouth", don't go to the point where it breaks. In the "Laijieer", the "seven inches and three quarters" place must be "retained". ......When the author's intention is pointed out, the subject is clear, but the subject is limited, and the meaning is lost. Novels are not suitable for topic. [48]

Wang Zengqi once said: "The novel is created by the author and the reader together. The author writes it, the reader reads it, and the creation process is completed...Short stories can be said to be'blank art'." Wang Zengqi said: "Blank is a short story. Features. It can be said that short novels are blank art. Chinese painting pays attention to the idea of'white space when black'... The so-called'blank' is simply to say less writing. Short novels are not made by deletion. The deletion is too harsh It can be seen from the novels, which are often unsmooth, discordant, and not'round'. You should control your pen when you write, and think about every sentence you catch: Is it possible not to write this sentence? Write as little as possible. Whatever is written is necessary, one sentence is one sentence. Those that have not been written still exist, and exist in the'up, down, left and right' of each sentence. Only in this way can the sentence have an aftertaste and a meaning... [49] $\mathrm{He}$ also said: "The work is done jointly by the author and the reader. ... A novel should leave room and a lot of blank space, so that readers can freely think about identification, judgment, and approval. "The only way to make the language of novels more suggestive is to write as little as possible. If you don't write, let the reader write. The ancients said: 'I have been a little bit less, and I have won a lot of others'. If you write less, you actually write more. This is a big deal...".[50] 
Zhu Guangqian also made a similar conclusion: the less you say and the more you keep unspoken, the greater, deeper, and more true the sense of beauty aroused. [51]

In addition, Wang Zengqi also proposed that writers should use four-character sentences more; to make the language lively, the sentences should be as short as possible.

\section{GET THROUGH CONTEMPORARY LITERATURE, CLASSICAL LITERATURE, FOLK LITERATURE, AND FOREIGN LITERATURE}

He said in "My Creative Career": Language is the most fundamental thing of national tradition. Without proficiency in the language of the nation, one cannot write literature with distinctive national characteristics. However, the national tradition I am talking about is a tradition that does not exclude any external influences, and the realism I am talking about is realism that can accommodate various genres. For example, modernism and stream of consciousness are not bad things in themselves. [52]

So I urge you young comrades, comrades who are beginners to write, not only look at the works of contemporary writers, but only the translated works. Be sure to look at our own classical works, classical prose, classical poetry, including Sanqu, and practice writing one by yourself. Write, enrich the unique language sense of our Chinese people. Works with no sense of language or slow language sense will not be beautifully written. ...Or you should also read and read Chinese opera and folk songs, especially folk songs. [53] "You cannot be a good novelist without reading a little bit of folk songs and folk tales." [54]

In his article "Return to Realism, Return to National Tradition", he pointed out: What I asked for myself is to return to realism and national tradition. I have also received the influence of foreign literature, including the influence of "stream of consciousness" works. ... But, in general, I still want to return to realism and national traditions. This kind of realism is realism that accommodates various schools; this kind of national tradition is a national tradition that incorporates the best of foreign cultures. The road should be wider. [55]

Mr. Qian Zhongshu put forward a statement: "Get through." Get through Chinese and Western literature. Wang Zengqi believes that the other kind of connection is the connection between contemporary literature and classical literature (national tradition). Needless to say, there is a huge gap between contemporary Chinese literature and classical literature. There is also a connection between contemporary literature, classical literature and folk literature. He believes that a contemporary Chinese writer should be a literary master. [56]

The author believes that this kind of "opening up" not only refers to the opening up of creative methods and art forms, but also refers to the opening up of language.

\section{CONCLUSION}

Wang Zengqi believes that language is not only form, but content itself. Writing a novel is writing language. In the history of modern and contemporary Chinese literature, there is hardly a second writer who puts language at the supreme position like him. Wang Zengqi's view of language is deeply influenced by traditional Chinese literary theories, including ancient Chinese literary theory and painting theory, especially by the eight great masters of the Tang and Song Dynasties, the Tongcheng School of Qing Dynasty, Han $\mathrm{Yu}$ and other literary language views. At the same time, he also absorbed the essence of May Fourth literature and foreign literature. Specifically, he inherited the "wenqi theory" of Han Yu and Tongcheng School in Qing Dynasty and carried it forward. His literary language "Leave Blank" is deeply influenced by Chinese painting theory. He inherited the aesthetic standards of literary language, such as Ouyang Xiu, Mei Yaochen, and Su Shi in Song Dynasty. Plainness is an important category of Wang Zengqi's language theory. He pointed out that the only criterion for literary language is accuracy. And because Chinese people use Chinese characters to think, Chinese characters have four tones and other characteristics. He especially emphasized that Chinese characters themselves are works of art, and writers must pay attention to the form, sound, and meaning of Chinese characters. Wang Zengqi believes that literary language has the characteristics of content, culture, fluidity, suggestion, and music. And the suggestiveness and fluidity of literary language is the first time that Wang Zengqi reveals. In order to enhance the personality and artistic expression of literary language, he also talked about the relationship between literary language and classical Chinese, spoken language, dialects, and blank spaces. He advocated seeking language resources from classical Chinese, spoken language, and dialects, and drew nourishment from classical literature and folk literature. In the New Culture Movement, $\mathrm{Hu}$ Shi advocated the use of vernacular Chinese instead of classical Chinese as a tool for new literature. Then Chen Duxiu clearly pointed out the "three major doctrines" in "Literary Revolution Theory", including "removing the obsolete and extravagant classical literature, and building a fresh and honest realistic literature." Now it seems that Chen Duxiu's proposition is undoubtedly a bit extreme. After 30 years of cultural gaps in 
contemporary Chinese literature, Wang Zengqi proposed to connect contemporary Chinese literature with Chinese classical literature in the 1980s. This is undoubtedly a reaction to Chen Duxiu's literary and artistic propositions. He made his own thoughts and explorations about where Chinese contemporary literature is headed. He intentionally or unconsciously used "Shen Congwen Style" as a language model. At the same time, it continues to move forward along the path of modernity transformation of literary language opened up by Shen Congwen. On this road, he went further than Shen Congwen. Shen Congwen upholds the theory of language "tool reinvention", while Wang Zengqi believes that language is not just a tool, it is itself a content, which elevates language to the status of ontology. From the characteristics of Chinese characters and Chinese, to the characteristics of literary language, to the aesthetic standards of literary language, and to how to improve the artistic expression of literary language, Wang Zengqi constructed a relatively complete theory of literary language. The outstanding features of this theory It is to give full play to the characteristics and advantages of Chinese characters and Chinese, and return to the national tradition. This "tradition" not only contains classical literature tradition, but also includes dialects, classical Chinese, spoken language and other resources. It has greatly enriched Chinese literary language theory and pointed out the direction for contemporary literary creation and linguistic research.

\section{REFERENCES}

[1] Wang Zengqi, Complete Works of Wang Zengqi", Volume 5, Beijing Normal University Press, PP.49,1998.

[2] Wang Zengqi, Complete Works of Wang Zengqi", Volume 3, Beijing Normal University Press, PP.30,1998.

[3] Wang Zengqi, Complete Works of Wang Zengqi", Volume 5, Beijing Normal University Press, PP.48-49,1998.

[4] Wang Zengqi, Complete Works of Wang Zengqi", Volume 6, Beijing Normal University Press, PP.496,1998.

[5] Wang Zengqi, Complete Works of Wang Zengqi", Volume 5, Beijing Normal University Press, PP.49, 1998 .

[6] Wang Zengqi, Complete Works of Wang Zengqi", Volume 4, Beijing Normal University Press, PP.301,1998.
[7] Wang Zengqi, Complete Works of Wang Zengqi", Volume 3, Beijing Normal University Press, PP.182,1998.

[8] Wang Zengqi, Complete Works of Wang Zengqi", Volume 3, Beijing Normal University Press, PP.184,1998.

[9] Wang Zengqi, Complete Works of Wang Zengqi", Volume 3, Beijing Normal University Press, PP.185,1998.

[10] Wang Zengqi, Complete Works of Wang Zengqi", Volume 4, Beijing Normal University Press, PP.232-233,1998.

[11] Wang Zengqi, Complete Works of Wang Zengqi", Volume 6, Beijing Normal University Press, PP.273,1998.

[12] Wang Zengqi, Complete Works of Wang Zengqi", Volume 5, Beijing Normal University Press, PP. 53,1998.

[13] Wang Zengqi, Complete Works of Wang Zengqi", Volume 4, Beijing Normal University Press, PP.233,1998.

[14] Wang Zengqi, Complete Works of Wang Zengqi", Volume 4, Beijing Normal University Press, PP.11-12,1998.

[15] Wang Zengqi, Complete Works of Wang Zengqi", Volume 4, Beijing Normal University Press, PP.13,1998.

[16] Wang Zengqi, Complete Works of Wang Zengqi", Volume 4, Beijing Normal University Press, PP.292,1998.

[17] Wang Zengqi, Complete Works of Wang Zengqi", Volume 4, Beijing Normal University Press, PP.217-218,1998.

[18] Wang Zengqi, Complete Works of Wang Zengqi", Volume 5, Beijing Normal University Press, PP.49,1998.

[19] Wang Zengqi, Complete Works of Wang Zengqi", Volume 4, Beijing Normal University Press, PP.218,1998.

[20] Wang Zengqi, Complete Works of Wang Zengqi", Volume 4, Beijing Normal University Press, PP.218,1998. 
[21] Wang Zengqi, Complete Works of Wang Zengqi", Volume 4, Beijing Normal University Press, PP.219,1998.

[22] Wang Zengqi, Complete Works of Wang Zengqi", Volume 4, Beijing Normal University Press, PP.303,1998.

[23] Wang Zengqi, Complete Works of Wang Zengqi", Volume 5, Beijing Normal University Press, PP.50,1998.

[24] Wang Zengqi, Complete Works of Wang Zengqi", Volume 4, Beijing Normal University Press, PP.220,1998.

[25] Wang Zengqi, Complete Works of Wang Zengqi", Volume 4, Beijing Normal University Press, PP.221,1998.

[26] Wang Zengqi, Complete Works of Wang Zengqi", Volume 6, Beijing Normal University Press, PP.497,1998.

[27] Wang Zengqi, Complete Works of Wang Zengqi", Volume 6, Beijing Normal University Press, PP.77,1998.

[28] Wang Zengqi, Complete Works of Wang Zengqi", Volume 4, Beijing Normal University Press, PP.222-223,1998.

[29] Wang Zengqi, Complete Works of Wang Zengqi", Volume 6, Beijing Normal University Press, PP.P52,1998.

[30] Wang Zengqi, Complete Works of Wang Zengqi", Volume 3, Beijing Normal University Press, PP.289, 1998 .

[31] Wang Zengqi, Complete Works of Wang Zengqi", Volume 4, Beijing Normal University Press, PP.11,1998.

[32] Wang Zengqi, Complete Works of Wang Zengqi", Volume 3, Beijing Normal University Press, PP.326,1998.

[33] Wang Zengqi, Complete Works of Wang Zengqi", Volume 3, Beijing Normal University Press, PP.289, 1998 .

[34] Wang Zengqi, Complete Works of Wang Zengqi", Volume 3, Beijing Normal University Press, PP.204,1998.
[35] Wang Zengqi, Complete Works of Wang Zengqi", Volume 3, Beijing Normal University Press, PP.313,1998.

[36] Wang Zengqi, Complete Works of Wang Zengqi", Volume 8, Beijing Normal University Press, PP.80,1998.

[37] Wang Zengqi, Complete Works of Wang Zengqi", Volume 5, Beijing Normal University Press, PP.109, 1998 .

[38] Wang Zengqi, Complete Works of Wang Zengqi", Volume 3, Beijing Normal University Press, PP.159-160,1998.

[39] Wang Zengqi, Complete Works of Wang Zengqi", Volume 4, Beijing Normal University Press, PP. 14,1998 .

[40] Wang Zengqi, Complete Works of Wang Zengqi", Volume 4, Beijing Normal University Press, PP. 15, 1998 .

[41] Wang Zengqi, Complete Works of Wang Zengqi", Volume 8, Beijing Normal University Press, PP.81,1998.

[42] Wang Zengqi, Complete Works of Wang Zengqi, Volume 6, Beijing Normal University Press, PP.334,1998.

[43] Wang Zengqi, Complete Works of Wang Zengqi", Volume 3, Beijing Normal University Press, PP.292-293,1998.

[44] Wang Zengqi, Complete Works of Wang Zengqi", Volume 3, Beijing Normal University Press, PP.293-294,1998.

[45] Wang Zengqi, Complete Works of Wang Zengqi", Volume 6, Beijing Normal University Press, PP.236,1998.

[46] Wang Zengqi, Complete Works of Wang Zengqi", Volume 4, Beijing Normal University Press, PP.105-106,1998.

[47] Wang Zengqi, Complete Works of Wang Zengqi", Volume 3, Beijing Normal University Press, PP.297,1998.

[48] Wang Zengqi, Complete Works of Wang Zengqi", Volume 3, Beijing Normal University Press, PP.298, 1998 . 
[49] Wang Zengqi, Complete Works of Wang Zengqi", Volume 4, Beijing Normal University Press, PP.44-45,1998.

[50] Wang Zengqi, Complete Works of Wang Zengqi", Volume 6, Beijing Normal University Press, PP.78,1998.

[51] Zhu Guangqian, The Beauty of Silence", "A Beautiful Life", Peking University Press. 7.PP.7,2008.

[52] Wang Zengqi, Complete Works of Wang Zengqi", Volume 6, Beijing Normal University Press, PP.495,1998.

[53] Wang Zengqi, Complete Works of Wang Zengqi", Volume 4, Beijing Normal University Press, PP.233,1998.

[54] Wang Zengqi, Complete Works of Wang Zengqi", Volume 3, Beijing Normal University Press, PP.203,1998.

[55] Wang Zengqi, Complete Works of Wang Zengqi", Volume 3, Beijing Normal University Press, PP.289-290,1998.

[56] Wang Zengqi, Complete Works of Wang Zengqi", Volume 5, Beijing Normal University Press, PP.247-248,1998. 